\title{
Research on Henan Academy Landscape Design Symbol

\author{
Take Songyang Academy as an Example
}

\author{
JunxiaYan \\ Huanghe Science and Technology College \\ Zhengzhou, China
}

\begin{abstract}
Garden is an important part of the space environment, is the practical art of serving the people's daily life, work and learning; at the same time, it plays important role in making people enjoyable and improving people's aesthetic ability. Making clear the design connotation (culture symbol) of Henan academy gardens in the Ming and Qing dynasties, function (creating a learning environment for the ancient scholars), method (design method, principle, material), regional elements and other symbols element, and arranging the design symbol system of Henan academy garden in the Ming and Qing dynasties, will provide enlightenment and reference for the design and practice of China modern campus landscape.
\end{abstract}

Keywords-Ming and Qing dynasties; academy garden; function; signification

\section{INTRODUCTION}

The research of the academy garden design symbol belongs to the research of landscape design in the environmental design and also belongs to the category of design semiotics. Landscape design has the characteristics of interdisciplinary interaction and borderline and comprehensiveness, and the applied perspective, method and means for the theory and practice research are constantly updating.

\section{A. Research Status}

There are numerous writings of design construction and academic research on Chinese and foreign classical garden design; at the same time, there are fruitful results in the academic research, method exploration, education and practice of Chinese classical garden design. According to the current status analysis of the domestic and foreign research of Chinese classical garden, the research in this field has presented the development trend of diversification, multiple points of view, and multi-disciplinary interaction, and the research achievements are also more and more profound.

For the research on Songyang Academy landscape design, the selected object of research is the academy garden. Relatively speaking, there are few researches of the scholars at home and abroad on the Chinese classical academy gardens. In recent years, many scholars of cultures, art, design science, architecture, and modern education perspective are conducting

Fund project: Phased achievement of 2016 humanities and social science research youth project "research on Henan academy garden design symbol in Ming and Qing dynasties" of Henan department of education, project number: 2016 - QN - 043 the multifaceted research and exploration on the academy gardens. For example, He Liping's "Cultural Significance of Chinese Ancient Academy Gardens" (2004), in Beijing forestry university, Yu Xiaoou's master graduation thesis "Academy Landscape Design Technique and Its Inspiration on Modern Campus Construction"(2010) and in Henan Agricultural University, Wan Yingna's master graduation thesis "Research on Henan Ancient Academy Garden Art" (2014) provide an important reference for the early basic research of this topic, especially for clearly the overview and artistic features of Henan ancient academy garden.

The result of research on landscape design is also very rich. Such as in Beijing Forestry University, Ding Ke's master graduation thesis "Application of Principles of Semeiology in Landscape Design (2005), and Zhang Yuangbo's thesis "Artistic Symbol Abstraction of Chinese Classical Garden" (2014), etc. At the same time, the famous French scholar, Roland Barthes's "Éléments de sémiologie" ("principle of Semeiology", translated by $\mathrm{Li}$ Youzheng in 1964) and $\mathrm{Hu}$ Fei's "Art Design Symbol Base" (2008) and other writings can provide the beneficial reference in the related theoretical framework, research perspectives and methods, etc.

\section{B. The Development Situation of Henan academy in the Ming and Qing Dynasties}

The academy was built in the Tang dynasty, got most prevalent in the Song dynasty, and was popularized in the Ming and Qing dynasties. Academy was the education institution in ancient China, meeting the scholars' demand for academic exchange and gathering, teaching, cultivating intellectuals, collecting books and making sacrifice, apprenticeships and leisure and so on. Academy garden building design is deeply influenced by Chinese classical gardens, and in the site selection, architectural form, spatial layout, cultural landscape forming (horizontal inscription board, couplet on the columns, inscriptions on tablet, inscriptions of scenic spots and architecture) and etc have the unique landscape form, reflecting the age characteristics of the specific period, with a profound cultural background. According to historical records, during the Song and Yuan dynasties, the academy development is most powerful and prosperous, and it is gradually declined in the Ming Dynasty. Due to the political reasons, the development of academy was in a state of silence in early Ming Dynasty, 
and till the middle Ming Dynasty, the academy was gradually developing well, in this way, many academies were created in Henan, such as Ziyun Academy in Xiangcheng, Zhuge Academy in Nanyang, Yiluo Academy in Luoyang, at the same time, some existing academies were repaired. But by the end of Ming Dynasty, the government ordered a "ceasing all private academies in China", followed by which, the private academies are prohibited and destructed, with more than $70 \%$ of the academies getting in the neck. Soon after, in Henan, a batch of academies were built by the officials, including "Talented and Virtuous Academy" in Zhenyang county, "Daqiu Academy in Yongcheng, "Huangchi Academy" in Neihuang county, "Dacheng Academy" in Dengzhou, "Runa Academy " in Xuchang and "Dacheng Academy" in Fugou county and "Huanghua Academy in Li county and others, totaling 14 academies. From early Qing Dynasty to the $32^{\text {nd }}$ year of Guangxu period (1905), total 322 academies of five levels were recorded in history books and local chronicles, including province, prefecture, state, county levels.

\section{HENAN ACADEMY GARDEN DESIGN SYMBOL S YSTEM IN THE MING AND QING DYNASTIES}

\section{A. The Establishment of the Formal Language}

Formal language construction is embodied by site selection and the type and space layout of academy building. As a place for academic exchanges and even sacrifice, the site selection of academy is especially emphasized. Henan academies in the Ming and Qing dynasties are most located in mountains or holy land or near the mountains and rivers, facing to the south, and some go up the steps in combination with the topography, on the one hand,being particular about ecosystem of the local environment, on the other hand, pursuing of quiet and beautiful learning atmosphere. For example Songyang Academy is located at the south of Songshan; Yingtian Academy is titled due to the Yingtian government office, and although it is located on a downtown street, the ideal of pursuing of "a man with great wisdom hidden in secular downtown" is sublimated, so as to cultivate intellectuals for calm and open mind.

Henan academy gardens in the Ming and Qing dynasties are affected by hierarchical idea in their architecture and space layout, and the Chinese classical academies mostly is planned in axisymmetric mode and natural flexible type. The regular central axisymmetric layout is full of orderly and rational aesthetics, which helps to create a solemn and dignified space atmosphere; and the natural and flexible layout mainly depends on the original terrain difference and trend. In the design of gardens of the academy buildings or courtyard, natural terrain or natural interest is followed. In the whole garden layout, winding corridors are designed that make the building and the nature reflecting each other, achieving the spiritual demand of the teachers and students for returning to their original nature and cultivating their moral characters.

The design language has symbolic meanings for Henan academy landscape, and the existing shapes and structures reserved are mostly made in the Qing Dynasty. Blue brick color and brownish red and other neuter color are composed and plain, more used for the exterior walls. In the courtyard, there are horizontal inscription boards and tablet inscriptions interspersed, showing the calligraphy and painting, philosophy, history and culture, becoming rich landscape ornaments, and presenting the unique cultural atmosphere of academy garden. The academy adopts the structure construction techniques of traditional garden landscape, such as the primary and secondary arrangement and comparison, ratio, guiding and suggesting, scene borrowing, view enframing etc., in pursuit of imitating the nature and going beyond the nature. The academy garden has simplicity and keeps quiet and elegant atmosphere, presenting the decorous temperament and interest of literati in a artistic way.

\section{B. Function}

Seen from the functions of academy, first of all, the indispensable functional construction includes gate, lecture room and books collecting building as well as the temple, the ancestral halls for sacrifices; and the landscape construction includes memorial arch, pavilion, corridors, pavilion etc. With functional architecture as the theme, it forms different yards, with landscape architecture ornamented in different space. Due to the different environment and regional culture, academy courtyard layout, building structure and color all have some differences.

In addition to education, library, sacrifice, the function of the academy is also a place for teachers and students enjoying sight and having a rest. The design of plants has an important position in the garden. Academy garden plant is combined with the characteristics of Chinese traditional private garden and temple garden, to form the unique space atmosphere. Henan is vast in territoriality, the academies in the dense area in the Ming and Qing dynasties have large difference. Due to the different geographical environment of the academy, the plants in the gardens have strong local culture, also reflect the unique disposition and artistic conception of the academies, meeting the aesthetic standard and value orientation of ancient scholars, expressing their boundless minds and spiritual sustenance, and giving people infinite imagination.

\section{Communication of Artistic Conception}

The meaning of the academy garden design symbols is mostly related to the Confucian culture, Taoist and Buddhist Zen culture, and the connotation of academy landscape design symbol integrates Confucian "family matters and national events, all are of the world", Taoist "natural inaction", Zen's " observing with clear mind". Thus, to really and thoroughly understand the nature of academy landscape design symbols, we must comprehensively and deeply study Confucianism, Buddhism, and Taoism culture. The school-running idea for the academy, the founders and their ideas, the construction method of the general academies, the spatial composition of building, the cultural and artistic atmosphere shaping all have influence and reference for the design language of the academies; The design principles and the design language application of the academy garden in the Ming and Qing dynasties play a positive role for cultivating talents.

The components of the academy garden space language are also reflected in the basic semantic communication of various decorative elements of basic symbol unit: (1)wood carvings, brick carvings, painting, stone carving, paving and decorating patterns etc., which in ancient China, occupied an important position in the history of Chinese calligraphy and of art, and 
besides the contents also can reflect the thought and social status that time; (2) the couplet, plaque and other specific text symbols reflect the long history of the academy and the mentoring relationship, and record the academic ideas and achievements of the academy.

The moral naming or functional naming was used in the scenic spots and buildings in the Academy. The applications in the different academy were varied. The scholars in Henan area are highlighted by the northerners' bold and straightforward characteristics, so the method of directly naming is used point out its functional characteristics, with rare euphemistic title of poetry, for example the buildings on each side of the Songyang Academy are directly named as "stele corridor", which can literally and clearly indicate the long corridor of the inscription.

\section{ANALYSIS ON THE SONGYANG ACADEMY GARDEN DESIGN SYMBOL}

Songyang Academy, located in Dengfeng, Henan, is an university in ancient China, and is also one of four ancient academies in China. In history, it was once the important place of Buddhism, Taoism, because its location in Songshan, where is the activity area of the Confucian school since ancient times, and there are also many other colleges, such as Nancheng Academy, Yingyu Academy, Shaoshi Academy and Cungu Academy, etc. Songyang Academy was built in the Northern Wei Dynasty, originally it was a religious site, and was used as academy from early Song Dynasty. Songyang Academy was repeatedly rebuilt in different periods. Its architectural layout maintains the style of the Qing Dynasty, and inherites the architectural style in the Song Dynasty. The north-south length of the cademy is 128 meters, and the east-west width is 78 meters, covering an area of 9984 square meters. There are existing five hundred halls and rooms, and the building appears axis layout on the whole, composed of five courtyards, successively including gate, Confucian Temple, auditorium, Orthodoxy Temple and library building. On both sides, there are book house, class room, teaching venue and other buildings.

Songyang Academy sits at north and faces to south. Its buildings are all along with the central axis, showing the layout of the courtyard, and the whole building has two deep axis, and on the principal axis, it has five courtyards, as the main building of academy. And on the principal axis of construction arrangement firstly is Xianshi temple (to worship past sages related to the academy), and subsequently is the classroom, then the Buddhist temple and finally the library building. On both sides, is "Chengzhu temple", book house, study building and etc. and in the west side yard is teaching venue building. The teaching venue buildings group is at the second axis, and the primary and secondary axes are relatively independent. Due to the influence of ancient Chinese etiquette, the superiors and inferiors class and primary and secondary order is highlighted in this layout, to achieve the goal from order to worship. The buildings mostly have a round ridge roof with gray ridgetile. The round ridge roof has a low construction level, and is a common roof style of civil building for ancient Chinese Han nationality, with smooth line, beauty of feminine tenderness. This kind of architectural form is very different from the other red walls and green tiles, and the carved beams and painted rafters in the central plains of China, has strong characters of literati architecture. Songyang Academy building reflects the modest, implicative, reserved and humble personality and people-oriented education thoughts of Confucius, regardless of rich or poor, old or young, all alike, are embraced.

On the interior bungalows wall, the scholars' inscriptions in all previous dynasties are inlaid, of which the handwriting and contents have respective distinctive features, no matter from the text content or font letter all directly reflect the values and talent of the academy teachers and students. The exterior wall color of academy is mainly based on blue brick color and brownish red, with quiet, elegant and solemn tone.

Songyang Academy is located at Zhongyue Songshan, with beautiful natural scenery, lush trees, mountain ranges, and rustic charm. The plant community in the academy is mainly based on the elm, acacia, weeping willow, Chinese white poplar, walnut and other native tree species, which formed the rich forest background. Around the academy, the orderly tower style Chinese junipers and Platvcladus orientalis Aurea Nana are orderly lined up, setting off the serious and solemn schoolrunning attitude; the soften the walls and fences make both the inside and outside environment of the academy have a naturally transition. Within the academy, it still keeps the vegetation community, retains the original tree species, and maximizes the protection of historical legacy, such as the famous tree "General Cypress", and other flowers, shrubs and grass are added, enriching the spatial arrangement of plant landscape. For the academy plant layout, the combination of regular and free plantings is adopted.

\section{CONCLUSION}

Campus landscape plays an important role in the teaching environment construction, reflects the unique quality of campus culture, and interprets the culture meaning of academy landscape design symbol, as well as the application methods and principles of landscape design symbol and etc., which can be directly applied in the practice process of current garden teaching. As the Feudal society's unique education organization and academic institution, the academy reflects the essence of Chinese classical garden art. The gardening technique and its implied educational thought have a profound influence on today's campus landscape design. The artistic conception communication of the garden symbols in the academy helps us fully combine with regional characteristics, functional requirements, campus culture, college location, spatial layout, ambience, cultural heritage, etc. in the design of campus landscape, to provide reference and to establish the college campus with good ecological environment, good connotation and regional characteristic according to the characteristics of today's campus environment, having a positive significance for the development of today's colleges and universities and the construction of new campus.

\section{REFERENCES}

[1] BaiXinliang:Chinese Ancient AcademyHistory [M]. Tianjin: Tianjin university press, 1995. 
[2] He Liping,ZhengJianmin: the culture meaning of Chinese ancient cultural academy gardens [J] Chinese garden, 2004.08.

[3] Kong Sumei, BaiXu: simple analysis on ancient Chinese academy architectural form- taking Chinatop four ancient academies as an example[J] architectural culture, 2011.07.

[4] Wan Yingna: Henan Agricultural University "Henan ancient garden art academy" (2014).

[5] Zhang Yuanbo: Chinese classical garden art "symbol" refining contemporary the Chinese national characteristics point easily searched for modern landscape design [C]. 2014 Annual meeting and academic seminar of Chinese architectural history association, 2014.

[6] Yu Xiaoou:Academy garden design method andthe inspiration of modern campus construction[D], Beijing Forestry University, 2010. 